\title{
Twenty years of LASSBio, the laboratory of evaluation and synthesis of bioactive substances!
}

Considering its fruitful contribution to the search for new molecules that potentially can be drugs, LASSBio, situated at the Federal University of Rio de Janeiro, has been representing the best of Brazilian Medicinal Chemistry for twenty years.

LASSBio is Professor Eliezer Barreiro's dream that comes true. Although formally created on April 19, 1994, the work of the previous group had started years before, as soon as Professor Eliezer returned from his $\mathrm{PhD}$ in France. Thanks to his hardworking and idealistic personality inspiring his students and colleagues, many obstacles have been overcome from that time on and the success arose as a consequence of competence, discipline and belief. Professors Lidia Moreira Lima and Carlos Manssour Fraga have been sharing the responsibility of LASSBio performance since they got their $\mathrm{PhD}$ under Professor Eliezer supervision.

Last September 25-26, a Workshop was held in the Federal University of Rio de Janeiro to celebrate 20 years of this Laboratory. More than a confraternization party, it represented a historical event and an example to new generations.

It is worth to note that more than one hundred of masters and doctors had been graduated in this Laboratory since it was born. Most of those graduated professionals are now in academia and have been nucleating new groups, expanding the knowledge they got from the original nucleus.

Following Ford statement, that says "Coming together is a beginning, staying together is progress, and working together is success", the group has joint together collaborators of many areas of knowledge, comprised by Drug Design, and succeeded. Many relevant scientific projects supported mainly by CNPq, FAPERJ, and also some pharmaceutical industries, allowed LASSBio to trigger the creation of INCt-INOFAR, National Institute of Science and Technology in drugs and medicines, a relevant and fruitful initiative supported by those financial agencies, constituting an example of organization that embraces teaching, knowledge generation, reflected by almost three hundred scientific papers, and important outreach activities.

Working on the design of new drug candidates for pain, inflammation, asthma, central nervous systems, cardiovascular system, cancer, metabolic diseases, and neglected diseases, they registered 15 patents, including international ones. More than one thousand and five hundred molecules were synthesized and evaluated so far, intending to obtain drug candidates for one or more of those therapeutic areas, as mentioned 


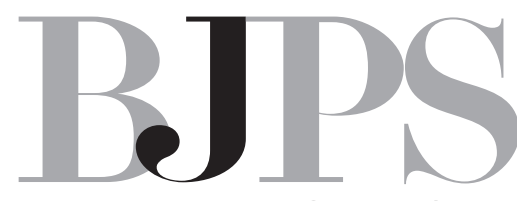

Brazilian Journal of Pharmaceutical Sciences

before. This solid library of molecules has been built using specially approaches as molecular simplification, and hybridization, this latter addressed to obtain symbiotic effect through the interaction with more than one target. The group has also being using molecular modeling as an important tool for understanding the physico-chemical aspects and the mechanism of action of the new molecules. This is a legacy for the present and future generations working on drug design and provides means to achieve Professor Eliezer's goal: "To discover a drug that speaks Portuguese!"

On behalf of Professor Eliezer Barreiro, congratulations to all who are partners in those 20 years of success!

Long live to LASSBio!

Elizabeth Igne Ferreira

Scientific Editor 